\title{
LA EDUCACIÓN EN CASA \\ O HOMESCHOOLING EN LA DOCTRINA DEL TRIBUNAL CONSTITUCIONAL
}

\author{
Miguel Ángel AsENSIO SÁNCHEZ \\ Profesor Titular de Derecho Eclesiástico \\ Universidad de Málaga \\ maasensio@uma.es
}

\begin{abstract}
RESUMEN
El homeschooling constituye un banco de pruebas adecuado para deslindar problemas jurídico-constitucionales de enorme importancia en relación con las libertades implicadas en el derecho a la educación. En último término se trata de explicitar si la libertad de enseñanza (art. 27.1 CE) y los derechos educativos paternos (art. 27.3 CE) permiten a los padres imponer a los hijos un modelo educativo como el del homeschooling en el que los padres, por motivos ideológicos, religiosos o pedagógicos, rechazan la escuela convencional e incumplen el deber de escolarización que la ley establece con la finalidad de garantizar el derecho/deber de cursar la enseñanza básica obligatoria (art. 27.4 CE). La clave de la cuestión es que las libertades educativas están subordinadas al interés del menor, principio informador del sistema educativo y que consiste en hacer efectivo el derecho a la educación y que ésta tenga por objeto el libre desarrollo de la personalidad y la transmisión de los valores constitucionales conforme al denominado diario constitucional (art. 27.2 CE). La doctrina del Tribunal Constitucional, aunque reconoce que la Constitución no identifica obligación de cursar la enseñanza básica con escolarización obligatoria, sí reconoce que esta opción por la que ha optado el legislador es la más adecuada para facilitar el derecho a la educación y garantizar el ideario constitucional y, en aras a la sacralización del mismo, limita los derechos educativos paternos cuyo ámbito de actuación principal sería fuera del horario escolar.
\end{abstract}

Palabras clave: Educación en casa, interés del menor, derecho a la educación, escolarización, pluralismo educativo, derechos educativos paternos.

\begin{abstract}
Homeschooling makes an adequate bank of samples to set out constitutional legal issues of an enormous importance in relation with freedom involved in the right to education. We ultimately need to clearly set out if the freedom of teaching (art. 27.1 of Spanish Constitution) and the parents right to their children's education (art. 27.3 of Spanish Constitution) allow the parents to impose on their children an educational model such as homeschooling where the parents reject conventional school and skip the right to enroll their children in a school based on their ideological, religious or educational beliefs. Such right is established by law so as to guarantee the right to/ duty of compulsory basic education (art. 27.4 Spanish Constitution). The crux of the matter resides in the fact that educational freedom
\end{abstract}


makes a condition of the minor's own interest, which is the premise of the educational system and which consists of exerting the right to education in a way that it will have as its main goal the free development of the person's character and the transfer of the constitutional values as stated by the so-called constitutional diary (art. 27.2 of Spanish Constitution). Even though the Constitutional Court doctrine claims that the constitution does not state the obligation to follow the basic primary and secondary education on a mandatory basis it does acknowledge the fact that this choice of the ruler is the most adequate to facilitate the right to education and to guarantee the constitutional principles which, so as to worship such right it restricts the parents educational rights to aside from school.

Keywords: homeschooling, minor's own interest, right to education, educational pluralism, parents' educational rights.

\section{ZUSAMMENFASSUNG}

Das Homeschooling wird zu einem Paradebeispiel bezüglich der Abgrenzung wichtiger juristisch-verfassungsrechtlicher Probleme in Bezug auf die impliziten Freibeitsrechte im Bereich der Erziebung. Im Letzten geht es darum, zu klären, ob unter Berufung auf das Recht auf Freibeit der Erziebung (Art. 27.1 der Spanischen Verfassung) und der elterlichen Erziehungsrechte (Art. 27.3 der Spanischen Verfassung) es den Eltern erlaubt ist, ibren Kindern ein Erziebungsmodell wie das Homeschooling aufzuzwingen, in dem die Eltern aus ideologischen, religiösen oder pädagogischen Gründen das herkömmliche Schulmodell ablebnen und der Pflicht zur Einschulung, die das Recht I die Pflicht zur gesetzlich garantierten Hauptschulpflicht umfasst (Art. 27.4 Spanische Verfassung), nicht nachkommen. Der entscheidende Punkt liegt darin, dass die Freibeitsrechte der Kindererziebung unter dem Recht des Minderjährigen rangieren, auf dem wiederum das staatliche Schulrechtssystem aufbaut, das seinerseits das Recht auf Schulbildung durchzusetzen hat. Die Schulbildung ibrerseits soll dazu beitragen, die Persönlichkeit des Minderjährigen zu entfalten und die verfassungsrechtlichen Werte zu vermitteln gemäss dem so genannten «Diario Constitucional» (Art. 27.2 der Spanischen Verfassung). Obwobl das Verfassungsgericht in seiner Lebrauffassung keine zwingende Pflicht darin siebt, die Schulausbildung durch die Teilnabme am staatlichen Schulsystem zu absolvieren, so stellt das Verfassungsgericht doch heraus, dass es das staatliche System für das geeignetste bält, um das Recht auf Schulbildung und die Vermittlung der Verfassungswerte zu garantieren. Um dieses staatliche Schulsystem zu schützen, beschränkt das Verfassungsgericht die elterlichen Rechte und verweist sie auf ibr Haupttätigkeitsfeld: die außerschulische Erziehung außerhalb der Schulzeiten.

Schlüsselwörter: Hausunterricht, Schutz der Rechte von Minderjährigen, Recht auf Schulbildung, Einschulung, Pluralismus in der Erziehung, die Erziehungsrechte der Eltern.

SUMARIO: I. INTRODUCCIÓN.-II. LA CONFIGURACIÓN JURÍDICA DE LA EDUCACIÓN EN CASA EN LA DOCTRINA DEL TRIBUNAL CONSTITUCIONAL: PLANTEAMIENTO Y CRÍTICA.-III. DEBER JURÍDICO DE ESCOLARIZACIÓN Y DEBER CONSTITUCIONAL DE CURSAR LA ENSEÑANZA BÁSICA: RELACIÓN JURÍDICO-CONSTITUCIONAL.-IV. EL 
FUNDAMENTO DE LA OBJECIÓN AL SISTEMA ESCOLAR: LA LIBERTAD DE ENSEÑANZA Y EL DERECHO DE LOS PADRES A EDUCAR A SUS HIJOS CON ARREGLO A SUS PROPIAS CONVICCIONES.-V. EL HOMESCHOLLING Y EL INTERÉS DEL MENOR.

\section{INTRODUCCIÓN}

Sin duda los avances que más han contribuido a la transformación de la sociedad han sido, de un lado, la elevación de la educación a la categoría de derecho fundamental del individuo, y de otro, y relacionado, el reconocimiento generalizado de la educación básica obligatoria como pilar esencial de la efectividad del mismo. Ello ha supuesto que el derecho a la educación tenga un carácter prestacional y conlleve la obligación por parte del Estado de implementar medidas encaminadas a garantizar el acceso de toda la población a la enseñanza básica obligatoria y gratuita ${ }^{1}$. Este fenómeno de universalización de la enseñanza básica ha sido posible gracias a otro paralelo y progresivo de escolarización, convirtiéndose la escuela en el principal vehículo del que se sirven las sociedades modernas para la difusión y transmisión no sólo de conocimientos, sino también de aquellos valores estimados socialmente relevantes y, por tanto, jugando un evidente papel político, de modo que la escolarización obligatoria se ha convertido en una característica antropológica de las sociedades modernas. No obstante, este carácter socializador e integrador propio de la escolarización no puede hacernos olvidar que la escuela no tiene el monopolio socio-educativo, aunque en ella la educación y socialización se realice y perciba socialmente de forma más intensa ${ }^{2}$.

El carácter universal alcanzado por el fenómeno de la escolarización hace que el individuo la perciba como una realidad normal e incontestable, que necesariamente debe cubrir una etapa significativa de la vida, sin que de ordinario surja el menor planteamiento crítico sobre si la escuela actual cumple o no el papel para el que fue creada ${ }^{3}$. No ocurre lo mismo

${ }^{1}$ No pretendo entrar aquí en la polémica de la enseñanza pública gratuita frente a la privada, sino únicamente reflejar la importancia social, económica y política que se le atribuye en todos los países a la necesidad de educar a la población hasta el punto de convertirla en uno de los quicios sobre los que gira la política socioeconómica de los países más avanzados.

2 M. A. Asensio SÁnCHEZ, «La objeción de conciencia al sistema escolar: la denominada educación en casa», Laicidad y libertades. Escritos jurídicos, núm. 6 (2006), pp. 12-18.

3 J. H. Gimeno SACRistán, La escolarización obligatoria: su sentido educativo y social, Madrid, Morata, 2000, pp. 9-12. 
en el pensamiento político y sociopedagógico, donde, y a pesar de reconocerse el papel insustituible que ha desempeñado hasta ahora y que con toda seguridad desempeñará en el futuro, no deja de ser objeto de numerosas críticas desde planteamientos educativos y políticos antagónicos que, a pesar de ello, coinciden en señalar las deficiencias de la escuela como espacio pedagógico y social (burocratización, conocimientos al margen del mercado, falta de coherencia curricular y desconexión con la vida, las esperanzas y las culturas de muchas comunidades) ${ }^{4}$. Los detractores más críticos de la escuela y su función sociopedagógica provienen de los partidarios de la denominada educación en casa y sus planteamientos antiescolares. La radicalidad de estos planteamientos estriba en poner en entredicho los binomios educación/escolarización y progreso socioeconómico/ escolarización, sobre la idea principal de que educar no es escolarizar y que la escuela tradicional no responde a sus planteamientos ideológicos y tampoco a las necesidades pedagógicas de la sociedad actual.

La educación en casa, más conocida por el nombre inglés de homeschooling, constituye una realidad educativa, relativamente nueva, surgida en Estados Unidos y no sólo como realidad educativa y pedagógica, sino que se enmarcan en un movimiento más amplio de contestación al Estado y su ingerencia en la vida de los ciudadanos.

El tratamiento de la educación en casa es diverso en el Derecho comparado. En algunos países se regula, en otros se prohíbe expresamente y en un país como Dinamarca se recoge en la Constitución ${ }^{5}$. Desde luego, en España no deja de ser un fenómeno residual, pero a pesar se ello constituye, a mi modo de entender, un banco de pruebas adecuado y útil para deslindar problemas jurídico-constitucionales de enorme importancia en relación con las libertades implicadas en el derecho a la educación. En realidad, la educación en casa plantea problemas de carácter constitucional cohonestados, en último término, con el ámbito y extensión del pluralismo

\footnotetext{
${ }^{4}$ Sobre el particular vid. M. W. Apple, Política, cultura y educación, Barcelona, Paidós, 1996; N. Fraser, Iustitia interruptus, Bogotá, Siglo del Hombre, 1997.

5 Es interesante para conocer la situación de la educación en casa en el Derecho comparado los trabajos de la profesora I. BRIONES MARTínEZ, «¿La escuela en casa o la formación de la conciencia en casa?», Revista General de Derecho Canónico y Derecho Eclesiástico, núm. 3 (2003); íD., «Aspectos constitucionales y jurisprudenciales de la educación en casa. Análisis comparativo entre Estados Unidos y España», I Congreso Nacional de Educación en Familia (bomeschooling), Valencia, 2010; M. ${ }^{\text {a J }}$. VAlero Estarellas, «Homeschooling en España, una reflexión acerca del art. 27.2 de la Constitución y del derecho de los padres a elegir la educación de sus hijos», Revista General de Derecho Canónico y Derecho Eclesiástico del Estado, núm. 28 (2012), pp. 2-18.
} 
educativo y con el derecho del menor a la educación. Además, al no aparecer regulada la educación en casa en nuestro ordenamiento y al existir un deber jurídico de escolarización sólo podría configurarse, tal y como veremos, como una objeción de conciencia y, consecuentemente, manifestación de las libertades educativas consagradas en el art. $27 \mathrm{CE}$.

El análisis de la doctrina del Tribunal Constitucional sobre el homeschooling, a pesar de ser escasa, limitada a la STC 260/1994, de 3 de octubre, y a la STC 133/2010, de 2 de diciembre, plantea los principales problemas jurídicos inherentes a este fenómeno. Fundamentalmente estos problemas se centran en explicitar, de un lado, si podría justificarse la educación en casa en las libertades educativas consagradas en el art. $27 \mathrm{CE}$, y de otro, si este modelo educativo podría ser lesivo para el derecho a la educación del menor y su interés.

La STC 260/1994 tiene lugar a resultas de ciertas actuaciones penales seguidas contra los miembros de la «secta de los Niños de Dios» por la Dirección General de la Atención a la Infancia de la Generalitat de Cataluña, que, en vista del riesgo posible para la salud física y mental de los menores convivientes en el grupo de los adultos inculpados, acordó asumir la tutela legal de los mismos y ordenó su internamiento en un centro público. Los padres se opusieron a la declaración de desamparo y a la asunción de la tutela legal por la Generalitat, llegando el asunto a la jurisdicción ordinaria. El juez de primera instancia acordó mantener la situación de tutela por la Administración; posteriormente se concedió la guarda provisional de los menores a sus padres, sin perjuicio de dicha tutela de la Administración. Los padres recurrieron la resolución del Juzgado ante la Audiencia Provincial, que estimó los recursos en varios autos por entender que no quedaba acreditado el carácter sectario del grupo y, por ello, que las enseñanzas recibidas por los menores respondían a las que el Estado consideraba básicas y obligatorias en el currículum académico. En el auto se argumentaba además que tales enseñanzas eran semejantes a las impartidas en centros oficiales ${ }^{6}$. La Audiencia entendió que la Generali-

${ }^{6}$ «Crean sus propio plan de estudios englobando un conjunto de materias proyectadas preferentemente sobre este ámbito desde un punto de vista autoritario, es decir, mediante la imposición de unas convicciones morales, filosóficas y religiosas conformes a su peculiar ideología, en primacía a la mera transmisión de conocimientos científicos que "si bien se imparten igualmente" lo son después de aquéllos considerados como básicos (escolaridad libre según el ordenamiento jurídico de alguno de los países de origen de los niños y, en definitiva, no dista de la que se da en los colegios regidos por religiosos en nuestro país), eludiendo especialmente la enseñanza superior en beneficio de la práctica (recomendación a favor de la formación profesional)» (SAP de Barcelona de 21 de mayo de 1992, FJ 6. ${ }^{\circ}$ ). 
tat había injerido de forma intolerable en el ámbito familiar y que, en cualquier caso, debía prevalecer la libertad de culto de los padres y el derecho a elegir la educación de los hijos.

El problema se planteó también ante el Tribunal Supremo y, posteriormente, ante el Constitucional. Acusados, entre otros delitos, de fundar centros de enseñanza ilegales, el Tribunal Supremo en Sentencia de 30 de octubre de 19947, que revoca la de la Audiencia de Barcelona, absuelve de los delitos que ésta estimaba fundados en la existencia de incumplimiento por los padres, sobre la base de sus creencias religiosas, del deber de dar a los hijos una educación integral.

Por su parte, la STC 260/1994, de 3 de octubre, conoció del mismo asunto al resolver un recurso de amparo interpuesto por la Generalitat de Cataluña contra la sentencia de la Audiencia. El fondo del asunto era si la situación escolar de los niños justificaba la privación de la tutela de los padres para asumirla la Generalitat, pero no entra en la cuestión de la objeción al sistema escolar que, por otro lado, estaba en la raíz de la negativa de los padres a la escolarización. En cambio, veremos como sí plantea el problema de la objeción escolar el voto particular de Gimeno Sendra.

No obstante, ya hemos afirmado, es la STC 133/2010, de 2 de diciembre, la única vez en la que el Tribunal Constitucional se había pronunciado directamente sobre la posibilidad de admitir la educación en casa, al margen de la escolarización obligatoria. Los hechos de los que traen causa la demanda son básicamente los siguientes: el Juzgado de Primera Instancia de Coín dictó Sentencia el 5 de mayo de 2003 ordenando a unos padres que escolarizaran a sus hijos menores de edad en el ciclo escolar básico en el curso 2003-2004. Fundamenta su decisión en que, sin juzgar la calidad de la enseñanza domiciliaria que estén recibiendo, y admitiendo que son familias bien estructuradas cuyos padres se preocupan por sus hijos, el art. 27.4 CE no permite que los padres nieguen a los hijos el derecho y la obligación que tienen de participar en el sistema oficial de educación.

Esta sentencia fue recurrida en apelación ante la Audiencia Provincial de Málaga. Se aducía incongruencia extra petita, pues, a juicio de los recurrentes, frente a la denuncia del Ministerio Fiscal referida al incumplimiento del art. 154 CC, el juzgador de primera instancia había desestimado la pretensión fundamentando su fallo en la obligatoriedad de la enseñanza establecida en art. 27.4 CE. La Audiencia negó la incongruencia extra peti$t a$, afirmando que los preceptos del Código Civil citados por los recurren-

\footnotetext{
RJ 1994/8334.
} 
tes derivaban del precepto constitucional referido y dictó Sentencia desestimatoria el 6 de junio de 2005. Asimismo, centró los términos del debate en si la educación que los menores recibían en su domicilio era suficiente para cumplir el mandato constitucional del art. 27.4 CE. Al respecto, la Sala afirmó que la escolarización estaba integrada en el concepto básico de derecho a la educación no sólo por los beneficios que los menores pueden tener mientras esta escolarización se desarrolla, sino también por los beneficios futuros en orden al aprendizaje en el marco de grados y titulaciones. El órgano de apelación arrancaba del voto particular del magistrado Vicente Gimeno Sendra en la STC 260/1994, de 3 de octubre, para llegar afirmar que el art. 27.3 CE ampara el derecho de los padres a impartir en el seno de la familia la enseñanza que estimen conveniente, enviar a sus hijos al colegio que deseen y exigir de los poderes públicos la formación que mejor se adecue a sus convicciones, pero no ampara el derecho de los padres a la no escolarización de los hijos bajo el pretexto de que sólo ellos sabrán impartir la educación adecuada. El órgano judicial recuerda que el derecho a ser escolarizado es un derecho del menor, no de los padres, que convive con la consiguiente obligación de los poderes públicos de procurar dicha escolarización, incluso imperativamente si ello fuera necesario.

En su demanda de amparo los recurrentes alegan, en primer lugar, la vulneración del derecho a la tutela judicial efectiva sin indefensión y a un proceso con todas las garantías (art. $24 \mathrm{CE}$ ), retomando la denuncia de incongruencia extra petita, si bien con argumentos matizados: por un lado, aducen que el art. 154 CC no resulta de aplicación al caso, pues está previsto para combatir el incumplimiento del deber escolar, fruto de la dejación de los deberes paterno-filiales, situación que no se produce en el presente supuesto, y por otro, denuncian que el órgano judicial falla estimando cuestiones no planteadas en la demanda, concretamente el grado de conocimiento que en las distintas materias y ramas existentes en el nivel educativo básico puedan tener los menores con respecto al sistema oficial reconocido, sin que ello fuese objeto de la demanda y exigiendo, además, la carga de la prueba a los demandados de algo para lo que ni siquiera se les ha requerido. Invocan también, en segundo lugar, la violación del derecho a la educación (art. 27.1, 2, 3 y 4 CE), en cuanto las resoluciones impugnadas deniegan a los menores el derecho a seguir su proceso educativo en su propio domicilio sin integrarse en el sistema escolar. Finalmente, oponen la vulneración del derecho a la no discriminación (art. $14 \mathrm{CE}$ ) por razón de nacionalidad, puesto que alguno de los recurrentes en amparo, que no son de nacionalidad española, tienen reco- 
nocidos en su país de origen el derecho a la enseñanza domiciliaria. En consideración a todo ello solicitan de este Tribunal que otorgue el amparo y declare la nulidad de la Sentencia de 5 de mayo de 2003, dictada por el Juzgado de Primera Instancia núm. 2 de Coín, y la Sentencia de 6 de junio de 2005, dictada en apelación por la Sección Quinta de la Audiencia Provincial de Málaga, así como que se reconozca el derecho a la educación en su domicilio. En la demanda de amparo se solicita también, mediante otrosí, la suspensión de la ejecución de las resoluciones impugnadas, toda vez que, de no accederse a la suspensión, el recurso de amparo perdería su finalidad. El Tribunal Constitucional, después de analizar que la decisión de imponer la escolarización obligatoria adoptada por el legislador mediante el art. 9 LOCE resulta constitucionalmente inobjetable, desestima el amparo.

\section{LA CONFIGURACIÓN JURÍDICA DE LA EDUCACIÓN EN CASA EN LA DOCTRINA DEL TRIBUNAL CONSTITUCIONAL: PLANTEAMIENTO Y CRÍTICA}

Existe un deber jurídico impuesto por el legislador de escolarización obligatoria entre los seis y los dieciséis años, y, en concreto, en el momento en que se dictó la Sentencia del Juzgado que motivó el recurso de amparo era la Ley Orgánica 10/2002, de 23 de diciembre, de Calidad de la Educación (LOCE), cuyo art. 9.1 disponía que: «La enseñanza básica comprende la Educación Primaria y la Educación Secundaria Obligatoria. La enseñanza básica es obligatoria y gratuita», y, además, conforme el núm. 2 del citado precepto: «La enseñanza básica incluye diez años de escolaridad. Se iniciará a los seis años de edad y se extenderá hasta los dieciséis».

Esta obligación legal de escolarización imposibilitaría la educación en casa de los hijos, obstáculo que las partes demandantes en amparo tratan de obviar alegando la existencia de una laguna legal sobre el particular que habría sido suplida por los órganos judiciales mediante una interpretación vulneradora de la libertad de enseñanza:

«En segundo lugar, en este contexto nos encontraríamos, al parecer de los recurrentes, ante una "laguna legislativa, pues no aparece en nuestra legislación nada referente a la enseñanza que no sea en centros docentes", de tal manera que los órganos judiciales, en lugar de "haber[la] suplido con una interpretación abierta y conforme al momento histórico, social y políti- 
co en que vivimos", la habrían integrado mediante una decisión vulneradora de la libertad constitucional señalada en primer lugar» ${ }^{8}$.

No obstante, el Tribunal Constitucional rechaza la existencia de una laguna legal y considera que la no escolarización de los hijos es contemplada por el ordenamiento como una conducta antijurídica que infringe un deber legal integrado en los deberes educativos paternos inherentes a la patria potestad (art. 154 CC):

«Ante todo, el origen de la lesión alegada en la demanda de amparo no se encontraría en las resoluciones judiciales impugnadas, sino, en su caso, en la disposición legislativa que éstas aplican puntualmente al supuesto de autos. En efecto, pese a lo que aducen los recurrentes, no nos encontramos aquí en modo alguno ante una laguna normativa: la cuestión de si la escolarización en la edad correspondiente a los hijos de los recurrentes en amparo debe o no ser obligatoria ha sido decidida expresamente, en sentido afirmativo, por el legislador, pues el art. 9 de la Ley Orgánica 10/2002, de 23 de diciembre (RCL 2002, 3012), de Calidad de la Educación (en adelante LOCE), vigente en el momento en que se dicta la sentencia del Juzgado aquí recurrida, establece que la enseñanza básica, además de ser obligatoria y gratuita (apartado 1) en los términos del art. 27.4 CE, "incluye diez años de escolaridad", de tal manera que se "iniciará a los seis años de edad y se extenderá hasta los dieciséis" [apartado 2; en el mismo sentido cfr. el vigente art. 4.2 de la Ley Orgánica 2/2006, de 3 de mayo (RCL 2006, 910), de Educación (en adelante LOE)]. Quiere ello decir que la conducta de los padres ahora recurrentes en amparo consistente en no escolarizar a sus hijos supone el incumplimiento de un deber legal —integrado, además, en la patria potestad— que resulta, por tanto, en sí misma antijurídica. No hay, pues, laguna normativa de ninguna clase»?

Efectivamente, tal y como afirma el Alto Tribunal, no existe una laguna legal y si el legislador hubiera querido que el derecho a la educación pudiera ejercitarse al margen de la escolarización hubiera regulado expresamente tal posibilidad; además, parece claro, el legislador ha unido derecho a la educación (art. 27.1 CE) y derecho/deber a cursar la educación básica obligatoria (art. 27.4) con la escolarización obligatoria. Por eso hasta que

${ }^{8} \mathrm{FJ} 4 .^{\circ}$

${ }^{9} \mathrm{FJ} \mathrm{4.}{ }^{\circ}$

Foro, Nueva época, vol. 15, núm. 2 (2012): 185-212 
no se modifique la legislación educativa la única posibilidad de admitir la educación en casa en nuestro ordenamiento es como objeción de conciencia $^{10}$. Ahora bien, otra cosa diferente sería la argumentación jurídico-constitucional que, en su caso, pudiera o no servir de fundamento para la admisión de dicha objeción.

Pero el Tribunal Constitucional no analiza el fenómeno de la educación en casa como un supuesto de objeción, sino que únicamente plantea la constitucionalidad o no de la escolarización obligatoria por si eventualmente lesiona el derecho a la libertad de enseñanza del art. 27.1 CE y el derecho de los padres a educar a sus hijos con arreglo a sus propias convicciones del art. 27.3 CE:

«Ha de precisarse a continuación que el examen de la queja aducida por los recurrentes conduce, en atención a lo que se acaba de señalar, a la necesidad de comprobar si la imposición normativa del deber de escolarización de los hijos de entre seis y dieciséis años, a cuyo cumplimiento sirven en el caso de autos las resoluciones judiciales impugnadas, es o no respetuosa con los derechos fundamentales alegados, resultando entonces procedente, a la vista del resultado que arroje ese examen, bien la desestimación del presente recurso de amparo, en caso de alcanzar una respuesta afirmativa, o bien la elevación de la cuestión al Pleno [art. 55.2 de la Ley Orgánica del Tribunal Constitucional (RCL 1979, 2383)], en el supuesto de que llegáramos a otra de signo contrario» ${ }^{11}$.

El planteamiento realizado por el Tribunal Constitucional no es acertado porque el hecho de que la norma que impone la escolarización no sea inconstitucional no acaba de resolver la cuestión de la posibilidad de objetar al sistema escolar. Es más, constituye un requisito previo para invocar la objeción que la ley que imponga el deber jurídico al que se objeta sea constitucional, ya que, de lo contrario, no procedería invocar la objeción, sino la inconstitucionalidad de la norma. En nuestra opinión, tal y como veremos, lo único decisivo para excluir a priori la educación en casa como una objeción sería que la Constitución identificara educación básica obligatoria con escolarización, puesto que no cabe objetar a un deber constitucional.

10 Ésta es mi tesis fundamental sobre la cuestión: M. A. AsENSIO SÁNCHEZ, «La objeción de conciencia al sistema escolar...», op. cit., pp. 34-44; íD., La patria potestad y la libertad de conciencia del menor, Madrid, Tecnos, 2006, pp. 83-89.

${ }^{11} \mathrm{FJ} 4 .^{\circ}$ 


\section{DEBER JURÍDICO DE ESCOLARIZACIÓN Y DEBER CONSTITUCIONAL DE CURSAR LA ENSEÑANZA BÁSICA: RELACIÓN JURÍDICO-CONSTITUCIONAL}

Analizado el hecho de que la educación en casa, mientras no se modifique la legislación, sólo puede invocarse en nuestro ordenamiento como una objeción de conciencia, se hace necesario explicitar si la Constitución une el deber de cursar la enseñanza básica a la escolarización, puesto que si así fuera, como es sabido, no puede objetarse a un deber constitucional.

La Constitución de 1978 consagra el derecho a la educación como un derecho fundamental cuyo objeto principal sería garantizar el pleno desarrollo de la personalidad humana (art. 27.2), lo que supone vincular directamente la actividad educativa con la dignidad de la persona y el libre desarrollo de la personalidad (art. 10.1). De este modo, el derecho a la educación se configura como un derecho de una marcada significación sociojurídica, especialmente por lo que hace referencia a la educación básica y la obligación de cursarla. Por eso la Constitución al cohonestar el derecho a la educación (art. 27.1) con la obligación de cursar la enseñanza básica (art. 27.4 $\mathrm{CE})$ refuerza la efectividad del derecho, de tal modo que el deber es correlativo al derecho a la educación y está a su servicio ${ }^{12}$. Esta efectividad se intensifica con la posición sistemática del derecho a la educación en la Sección I, «De los derechos fundamentales y de las libertades públicas», del Capítulo II, «Derechos y libertades», del Título I, «De los derechos y deberes fundamentales», y, consecuentemente, acreedor de la máxima protección jurídico-constitucional prevista en los núms. 1, 2 y 3 del art. 53 CE. Esta posición privilegiada permite reclamar ante los tribunales el aspecto prestacional del derecho a la educación: el derecho a cursar la enseñanza básica. Este importante papel atribuido a la enseñanza obligatoria no sólo como transmisión de conocimientos y competencias básicas, sino también de los principios y valores democráticos ${ }^{13}$, lo que ha posibilitado es caracterizar a la enseñanza básica obligatoria como «defensa de la Constitución» ${ }^{14}$.

El deber constitucional de cursar la enseñanza obligatoria va encaminado a garantizar la efectividad del derecho a la educación, y, lógicamen-

${ }_{12}$ M. A. Asensio SÁnCHEZ, «La objeción de conciencia al sistema escolar...», op. cit., pp. 19-20.

${ }_{13}$ Ibid., pp. 25-26.

14 A. M. ${ }^{a}$ ReDOndo, Defensa de la Constitución y enseñanza obligatoria (integración intercultural y homeschooling), Valencia, Tirant lo Blanch, 2003, pp. 74-77. 
te, la escolarización persigue la misma finalidad. Por eso la escolarización participa del carácter de derecho/deber propio de la enseñanza básica a cuya satisfacción está subordinada. El aspecto de derecho de la escolarización consiste en poder reclamarse judicialmente. El aspecto de deber aparece reforzado por otras normas dirigidas a garantizar su cumplimiento. Así, el art. 13.2 de LO 1/1996, de 15 de enero, de Protección Jurídica del Menor, establece que toda persona que tenga conocimiento de la no escolarización de un niño o su no asistencia al centro escolar de forma habitual y sin justificación deberá ponerlo en conocimiento de la autoridad competente. Además, el absentismo escolar está considerado por los tribunales como abandono de familia. El art. $226 \mathrm{CP}$ establece una pena de arresto de ocho a veinte fines de semana para quien dejare de cumplir los deberes legales inherentes a la patria potestad, entre los que se incluye el deber de educar a los hijos y procurarles una educación integral mediante la escolarización (art. $154 \mathrm{CC}$ ).

Ahora bien, aquí lo que nos interesa es si este deber de escolarización está incluido en el deber constitucional de cursar la enseñanza básica obligatoria (art. 27.4 CE) y, en último término, en el derecho a la educación (art. 27.1 CE), de modo que si la escolarización fuera un deber constitucional, la educación en casa no podría invocarse como una objeción. En nuestra opinión, es el ámbito subjetivo de estos deberes el que nos permitirá determinar la relación en que se encuentran. Se trataría de explicitar si ambos deberes obligan a los mismos individuos, porque de ser así podría entenderse que se trataría de dos formulaciones jurídica de un mismo deber; por el contrario, si los sujetos obligados fueran distintos estaríamos ante dos deberes jurídicos diferentes, aunque, lógicamente, relacionados.

Así, la obligación de cursar la enseñanza básica del art. 27.4 CE está subordinada a la efectividad del derecho a la educación, y siendo éste un derecho de todo individuo, sin estar vinculado a una determinada edad, se inferiría que también el deber alcance a todos independientemente de su edad. Es por eso que la LOE en el Título II, «Equidad en la educación», dedica el Capítulo IX a la educación de adultos, estableciendo una oferta educativa concreta dirigida a facilitarles la adquisición de las competencias y conocimientos correspondientes a la educación básica ${ }^{15}$. La educación básica de los adultos se considera voluntaria y sin escolarización oficial, si bien se establece la obligación de arbitrar medios por parte de la Administración educativa al objeto que puedan obtener el título de graduado en

${ }^{15}$ Art. 68.1. 
educación secundaria obligatoria siempre que acrediten haber alcanzado las competencias y objetivos de dicha etapa ${ }^{16}$.

En cambio, el obligado a la escolarización es sólo el menor de edad entre los seis y los dieciséis años, y fuera de esos límites de edad no obliga, con lo que parece evidente que la Constitución no identifica deber de cursar la enseñanza básica con escolarización, siendo dos derechos distintos, puesto que si no se daría la paradoja que la escolarización, al igual que la obligación de cursar la enseñanza básica, obligaría a todos sin límite de edad, lo que sería absurdo. Me parece claro que la Constitución no impone un deber de escolarización y no identifica enseñanza obligatoria con escolaridad; sólo impone el deber de cursar la enseñanza básica, lo cual puede hacerse a través de la escolarización o inclusive, en su caso, al margen de la enseñanza reglada acreditando los conocimientos y competencias propios de dicho grado de enseñanza. Esto no significa, en modo alguno, que la escolarización obligatoria sea inconstitucional, sino que el legislador ha optado por ella para facilitar y garantizar el cumplimiento del deber de cursar la enseñanza obligatoria en unas edades en que, desde el punto de vista sociopedagógico, se consideran las más proclives y adecuadas a la escolarización de los alumnos.

El Tribunal Constitucional, tal y como hemos señalado, se había pronunciado sobre la constitucionalidad de la norma que impone la escolarización obligatoria, para a continuación plantearse si el art. 27.4 CE constitucionaliza la escolarización obligatoria. Según el Alto Tribunal, el art. 27.4 CE no constitucionaliza la escolarización obligatoria, aunque considera acertado que el legislador opte por ella para cumplir el mandato de garantizar el derecho de todos a la educación mediante la programación general establecida en el art. 27.5 CE y para el cumplimiento y desarrollo del denominado ideario educativo constitucional del art. 27.2 CE y, además, es el modo de hacer efectivo el derecho a la educación del art. 27.1 CE:

«El art. 27.4 CE dispone que la enseñanza básica será obligatoria, pero no precisa que ésta deba configurarse necesariamente como un periodo de escolarización obligatoria, de tal manera que la decisión del legislador de imponer a los niños de entre seis y dieciséis años el deber de escolarización en centros docentes homologados - y a sus padres el correlativo de garantizar su satisfacción-, lejos de ser una operación de pura ejecución constitucional, es una de las posibles configuraciones del sistema entre las que aquél puede optar en ejercicio del margen de libre apreciación política que

16 Art. 68.2.

Foro, Nueva época, vol. 15, núm. 2 (2012): 185-212 
le corresponde en virtud del principio de pluralismo político. No obstante, esta configuración legislativa se compadece con el mandato en virtud del cual los poderes públicos deben "garantiza[r] el derecho de todos a la educación mediante la programación general de la enseñanza” (art. 27.5 CE), responde a la previsión de que "inspeccionarán y homologarán el sistema educativo para garantizar el cumplimiento de las leyes” (art. 27.8 CE), y, por lo que aquí más interesa, encuentra su justificación en la finalidad que ha sido constitucionalmente atribuida a la educación y al sistema diseñado para el desarrollo de la acción en la que ésta consiste, que "tendrá por objeto el pleno desarrollo de la personalidad humana en el respeto a los principios democráticos de convivencia y a los derechos y libertades fundamentales" (art. 27.2 CE). La educación a la que todos tienen derecho y cuya garantía corresponde a los poderes públicos como tarea propia no se contrae, por tanto, a un proceso de mera transmisión de conocimientos [cfr. art. 2.1.b) LOE], sino que aspira a posibilitar el libre desarrollo de la personalidad y de las capacidades de los alumnos [cfr. art. 2.1.a) LOE] y comprende la formación de ciudadanos responsables llamados a participar en los procesos que se desarrollan en el marco de una sociedad plural [cfr. art. 2.1.d) y k) LOE] en condiciones de igualdad y tolerancia, y con pleno respeto a los derechos y libertades fundamentales del resto de sus miembros [cfr. art. 2.1.b) y c) LOE].

Este objetivo, complejo y plural, es el que, conforme al art. 27.2 CE, ha de perseguir el legislador y el resto de los poderes públicos a la hora de configurar el sistema de enseñanza dirigido a garantizar el derecho de todos a la educación, y el mandato de su consecución es el principio constitucional al que sirve la imposición normativa del deber de escolarización en el marco de la enseñanza básica obligatoria (arts. 9.2 LOCE y 4.2 LOE). Un principio, por lo demás, que no sólo opera como directriz que la Constitución impone a los poderes públicos, y muy singularmente al legislador (art. 27.2, 4, 5 y 8 CE), sino que integra el contenido de la dimensión prestacional del derecho de los niños a la educación (art. 27.1 CE). Incluso en el caso de que la decisión de los padres de no escolarizar a sus hijos pretendiera ampararse en el ejercicio del derecho reconocido en el art. 27.3 CE, la imposición normativa del deber de escolarización y la garantía jurisdiccional de su efectividad encontrarían justificación constitucional en el mandato dirigido a los poderes públicos por el art. 27.2 CE y en el derecho a la educación que el art. 27.1 CE reconoce a todos, incluidos los hijos de los ahora recurrentes en amparo [STC 260/1994, de 3 de octubre (RTC 1994, 260), FJ 2. ${ }^{\circ}$ in fine]» ${ }^{17}$.

$\left.{ }^{17} \mathrm{FJ} \mathrm{7.}{ }^{\circ}, a\right)$. 


\section{EL FUNDAMENTO DE LA OBJECIÓN AL SISTEMA ESCOLAR: LA LIBERTAD DE ENSEÑANZA Y EL DERECHO DE LOS PADRES A EDUCAR A SUS HIJOS CON ARREGLO A SUS PROPIAS CONVICCIONES}

Después de haber tratado de justificar que la educación en casa, mientras no se modifique la legislación, sólo puede configurarse en nuestro ordenamiento como una objeción, corresponde explicitar cuál sería el fundamento que posibilitaría el reconocimiento de dicha objeción. En este sentido, los padres demandantes en amparo argumentan la pretensión de educar a sus hijos en el propio hogar, al margen de la escuela, en la libertad de enseñanza reconocida en el art. 27.1 CE y en el derecho que asiste a los padres para que sus hijos reciban la formación religiosa y moral que esté de acuerdo con sus propias convicciones del art. 27.3 $\mathrm{CE}^{18}$. Estas libertades educativas proyectan en el ámbito educativo la libertad ideológica y religiosa (art. $16 \mathrm{CE}$ ) y el pluralismo como valor superior del ordenamiento (art. 1.1 CE) y, en último término, garantizan a la sociedad y a los padres un papel primordial en la educación.

El Tribunal Constitucional afirma que si bien la libertad de enseñanza faculta a cualquier persona, y desde luego a los padres, a enseñar libremente fuera del horario escolar, no obstante, dicha libertad, por lo que atañe a la enseñanza básica, tiene su cauce de realización específico dentro del sistema educativo diseñado por la Constitución:

«En lo que respecta a la enseñanza que se desarrolla al margen de este último, las resoluciones impugnadas y las normas que éstas aplican no impiden en modo alguno que los recurrentes enseñen libremente a sus hijos fuera del horario escolar. Por lo que atañe a la enseñanza básica, la libertad de enseñanza de los padres encuentra su cauce específico de ejercicio, por expresa determinación constitucional, en la libertad de creación de centros docentes (art. 27.6 CE). La libertad de enseñanza de los padres se circunscribe en este contexto, por tanto, a la facultad de enseñar a los hijos sin perjuicio del cumplimiento de su deber de escolarización, de un parte, y a la facultad de crear un centro docente cuyo proyecto educativo, sin perjuicio de la inexcusable satisfacción de lo previsto en

${ }^{18} \mathrm{FJ} \mathrm{4}{ }^{\circ}$

Foro, Nueva época, vol. 15, núm. 2 (2012): 185-212 
el art. 27.2, 4, 5 y 8 CE, se compadezca mejor con sus preferencias pedagógicas o de otro orden» ${ }^{19}$.

El Tribunal Constitucional circunscribe la libertad de enseñanza y el pluralismo educativo a la elección por los padres de un puesto escolar dentro del sistema educativo, público o privado, y no contempla otras posibles manifestaciones del pluralismo, como es la educación en casa, que en un Estado democrático constituyen un baluarte de defensa del individuo y la sociedad frente a las eventuales imposiciones de determinadas concepciones antropológicas y/o sociales y que conllevan un ataque desde el poder político al pluralismo y una ruptura de la necesaria neutralidad que debe presidir la acción educativa del Estado. Además, una afirmación excesiva de la escolarización como clave de la educación llevaría a la paradoja de convertirla en fin mismo del sistema educativo y no en lo que realmente es, un medio del ejercicio efectivo del derecho a la educación, confundiendo fin con medio ${ }^{20}$.

El otro argumento aducido por los padres recurrentes en amparo para defender la no escolarización era precisamente el derecho a la educación del art. 27.1 CE. A este respecto, el Tribunal Constitucional entiende que el derecho a la educación no ampara la no escolarización, y ello a pesar de que, como hemos afirmado, la obligación constitucional de cursar la enseñanza básica no aparece unida en la Constitución a la escolarización obligatoria. A juicio del Tribunal Constitucional, el derecho de los padres a decidir el modelo educativo aplicable a los hijos se limita a la libertad para elegir el centro escolar y al derecho a que sus hijos reciban una formación religiosa y moral que esté de acuerdo con sus propias convicciones (art. 27.3 CE) y, en concreto, no considera que la escolarización obligatoria impuesta en la ley lesione el derecho de los padres:

19 FJ 5.

20 Son suficientemente esclarecedoras sobre los posibles peligros de la escolarización obligatoria para el pluralismo político las siguientes afirmaciones de Meléndez-Valdés Navas: «El papel que juega la escolarización obligatoria como medio de desarrollo y garantía del derecho a la educación no debe dejar de lado la valoración de ésta como medio y no como fin. Es por ello que lo calificamos de paradojas solamente en relación a aquellos casos en los que no se convierte en el instrumento que facilita el acceso a la educación, sino que lo dificulta. Tampoco se puede dudar que la escolarización obligatoria se constituyó como una manera o un instrumento adecuado para configurar y construir un nuevo modelo de ciudadano que viene determinado por el poder y su tendencia a querer controlar la vida social» [M. MelÉNDEZ-VALdÉS NAVAS, «Educación para la ciudadanía, homeschooling y pluralismo educativo», en J. R. Polo SABAu (coord.), Anuario de Derecho a la Educación, Madrid, Dykinson, 2012, pp. 233-234. 
«La facultad invocada por los recurrentes tampoco está comprendida, en segundo lugar, en el derecho de todos a la educación (art. 27.1 CE), que, dejando ahora a un lado su dimensión prestacional, no alcanza a proteger, en su condición de derecho de libertad, la decisión de los padres de no escolarizar a sus hijos. Efectivamente, en lo que respecta a la determinación por los padres del tipo de educación que habrán de recibir sus hijos, ese derecho constitucional se limita, de acuerdo con nuestra doctrina, al reconocimiento prima facie de una libertad de los padres para elegir centro docente [ATC 382/1996, de 18 de diciembre (RTC 1996, 382), FJ 4. ${ }^{\circ}$ ] y al derecho de los padres a que sus hijos reciban una formación religiosa y moral que esté de acuerdo con sus propias convicciones (art. 27.3 CE)» ${ }^{21}$.

Ahora bien, para explicitar si el derecho de los padres a educar a sus hijos con arreglo a sus propias convicciones les faculta para imponerles un modelo educativo sin escolarización, la clave reside en determinar la titularidad del derecho y, en concreto, si es un derecho de los padres, o bien un derecho de los hijos actuado por representación paterna ex art. 162.1 CC, y así poder prefijar la naturaleza y el contenido del derecho.

Un sector de la doctrina considera que se trataría de un derecho de los hijos que los padres ejercen en su nombre y representación ${ }^{22}$. Esta tesis considera la elección paterna del sistema educativo como un acto de ejercicio por representación legal de un derecho de la personalidad del hijo que, de acuerdo con las leyes y sus condiciones de madurez, no puede realizar por sí mismo, según se desprende, a sensu contrario, del art. 162.1 $\mathrm{CC}^{23}$. Este planteamiento parte de una inadecuada intelección del precepto, puesto que precisamente lo que hace éste es excluir de la representación paterna los derechos personalísimos del menor.

Otro sector de la doctrina alude al concepto de derechos educativos paternos, justificados en la institución de la patria potestad ${ }^{24}$, en los que incluye el derecho de los padres a decidir sobre la formación religiosa y moral de sus hijos, la elección de centros docentes y el derecho a participar

21 FJ 5. $\left.{ }^{\circ}, b\right)$.

22 J. L. Martínez López-MuÑIz, «La educación en la Constitución española (derechos fundamentales y libertades públicas en materia de enseñanza)», Persona y Derecho, vol. 6 (1979), p. 245; J. M. ${ }^{a}$ CONTRERAS MAZARIO, La enseñanza de la religión en el sistema educativo, Madrid, Centro de Estudios Políticos, 1992, p. 61; I. DE LOs Mozos TouYA, Educación en libertad y concierto escolar, Madrid, Montecorvo, 1984, pp. 78 y 177-180.

23 I. DE los Mozos TouyA, Educación en libertad y concierto escolar..., op. cit., p. 83.

24 A. Embid Irujo, «El contenido del derecho a la educación», Revista Española de Derecho Administrativo, t. 31 (1981), p. 674. 
en el control y gestión de los centros sostenidos con fondos públicos ${ }^{25}$. A juicio de estos autores, estos derechos no son del hijo, sino de los padres ${ }^{26}$.

En nuestra opinión, el derecho de los padres a educar a sus hijos con arreglo a sus propias convicciones sería desde luego un derecho de los padres y no del hijo. Así se infiere del tenor literal del art. 27.3 CE, del art. 2.1.c) LOLR, de los Tratados Internacionales en la materia ratificados por España y del art. 162.1 CC que, al excluir de la representación paterna los derechos fundamentales, impide interpretar este derecho como un ejercicio por representación del derecho fundamental del hijo a la educación, y, además, el art. 6.3 de la LO 1/1996, de 15 de enero, de Protección Jurídica del Menor, establece que los padres tienen «el derecho y el deber de cooperar para que el menor ejerza su libertad de conciencia de modo que mejor contribuya a su desarrollo integral $\gg^{27}$. No obstante, se trata de un derecho sui generis que, al derivar de los deberes educacionales inherentes a la titularidad de la patria potestad (arts. 154 CC y 39.1 CE), participaría de la naturaleza de función propia de esta institución. Es decir, este derecho constitucional de los padres estaría encaminado a facilitarles el cumplimiento de los deberes educacionales inherentes a la patria potestad, de modo que el art. 27.3 CE vendría no sólo a constitucionalizar los derechos educativos paternos, sino también los deberes. Esta naturaleza de derecho/deber vinculado a la patria potestad justificaría no sólo la subordinación de este derecho a la efectividad del derecho a la educación del menor, sino también que se extinga cuando cese la patria potestad o acabe la finalidad para la que se otorgó y, por tanto, cuando el menor pueda ejercer autónomamente el derecho a la libertad religiosa e ideológica, que, como sabemos, es cuando adquiera la capacidad natural de obrar ${ }^{28}$. De este modo, la faceta de derecho del art. 27.3 CE quedaría extinguida, permaneciendo, sin embargo, el deber, lo que es plenamente congruente con el carácter de función de la patria potestad de donde derivan los derechos educativos paternos.

El contenido del derecho de los padres a educar a sus hijos con arreglo a sus propias convicciones aparece lógicamente mediatizado por su naturaleza de función: derecho concedido para facilitar el cumplimiento de un

\footnotetext{
${ }^{25}$ Ibid., p. 673.

${ }^{26}$ C. CognetTi, Patria potestà e educazione religiosa dei figli, Milán, Giuffrè, 1964, p. 87.

${ }^{27}$ En este mismo sentido los arts. 5 y 14.2 de la Convención de los Derechos del Niño de 20 de noviembre de 1989.

${ }_{28}^{2}$ M. A. Asensio Sánchez, La patria potestad y la libertad de conciencia..., op. cit., pp. 36-42.
} 
deber. De este modo, en cuanto derecho, se ejerce siempre frente al Estado, nunca frente a los hijos, y consiste, básicamente, en poder exigir a la Administración, por un lado, la puesta en funcionamiento de los medios materiales necesarios para la satisfacción del derecho a la educación y, por otro, que sus hijos no reciban una educación contraria a sus convicciones. Este derecho se extendería también a la elección por los padres de la enseñanza moral y religiosa que estimen conveniente. Básicamente estos derechos se concretan en la elección de centro, al ser el medio más apto para satisfacerlo, aunque no se agoten ahí y mucho menos se identifiquen ${ }^{29}$. En cuanto a los deberes educativos paternos, se concretan en procurarles una formación, al menos la obligatoria, y que además cumpla los parámetros de una educación en interés del menor, básicamente ajustada al ideario educativo constitucional reconocido en el art. 27.2 CE, tal y como veremos.

El Tribunal Constitucional parte de la concurrencia de derechos de los padres y del Estado sobre la educación de los hijos ${ }^{30}$ :

«El alcance de la restricción operada por la decisión de configurar la enseñanza básica como un periodo de escolarización obligatoria en el contenido protegido por el derecho de los padres reconocido en el art. $27.1 \mathrm{y}$ $3 \mathrm{CE}$ ha de ser en todo caso relativizado en la medida en que, según se ha advertido ya, no impide a éstos influir en la educación de sus hijos, y ello tanto fuera como dentro de la escuela: dentro de ella porque los poderes públicos siguen siendo destinatarios del deber de tener en cuenta las convicciones religiosas particulares, y también fuera de ella porque los padres continúan siendo libres para educar a sus hijos después del horario escolar y durante los fines de semana, de modo que el derecho de los padres a educar a sus hijos de conformidad con sus convicciones morales y religiosas no resulta completamente desconocido» ${ }^{31}$.

Es más, el constitucional parece dar a entender la primacía del Estado en la educación frente a los padres, cuyo derecho se reduce al respeto a sus convicciones religiosas en el horario escolar y a la posibilidad de

${ }^{29}$ I. DE LOS Mozos TOuYA, «La posición jurídica de los protagonistas de la actividad educativa ante la escolarización en la enseñanza obligatoria», en Escolarización del alumnado en el sistema educativo español: cuestiones jurídicas, Madrid, Fundación Europea Sociedad y Educación, 2006, pp. 177-183.

${ }^{30}$ C. Garcimartín Montero, «Educación en el Estado laico: ¿de quién es el derecho?», en J. R. Polo SAbau (coord.), Anuario de Derecho a la Educación, Madrid, Dykinson, 2012, p. 87.

${ }^{31} \mathrm{FJ} \mathrm{8.} .^{\circ}$ 
educarlos fuera de dicho horario. Inclusive, el propio Tribunal reconoce que de otro modo el derecho de los padres a educar a sus hijos resultaría completamente desconocido e introduce una concepción del iter educativo en modo alguno avalada por la pedagogía y la legislación no como un proceso unitario y coherente, sino como una suma de concepciones antagónicas que eventualmente pueden contrarrestarse. El propio Tribunal reconoce que la medida alternativa propuesta por los recurrentes es menos restrictiva desde la perspectiva del derecho de los padres reconocido en el art. 27.3 CE, pero en modo alguno resulta igualmente eficaz para cumplir el mandato que la Constitución dirige a los poderes públicos en el art. 27.2 CE.

No obstante, en el caso que motiva la STC 132/2010, los argumentos aducidos por los padres para justificar la no escolarización de los hijos son pedagógicos y no de carácter ideológico o religioso. Para el Tribunal Constitucional el hecho de rechazar los padres la enseñanza oficial por motivos pedagógicos no se encuentra dentro del ámbito del derecho de los padres contenido en el art. 27.3, ya que éste derecho sólo hace referencia a motivos ideológicos y religiosos o morales, no pedagógicos:

«Un derecho éste que, pese a la apodíctica afirmación realizada en tal sentido por los recurrentes, no se ve comprometido en el presente supuesto, en el que las razones esgrimidas por los padres para optar por la enseñanza en casa no se refieren en modo alguno al tipo de formación moral o religiosa recibida por sus hijos, sino a razones asociadas al "fracaso escolar de la enseñanza oficial" e imputadas a la "asistencia obligatoria a esos centros oficiales, ya sean públicos o privados". Más allá de este doble contenido, el derecho a la educación en su condición de derecho de libertad no alcanza a proteger, siquiera sea prima facie, una pretendida facultad de los padres de elegir para sus hijos, por razones pedagógicas, un tipo de enseñanza que implique su no escolarización en centros homologados de carácter público o privado» ${ }^{32}$.

No obstante, el art. 14 de la Carta de los Derechos Fundamentales de la Unión Europea reconoce el derecho de los padres a garantizar la educación y la enseñanza de sus hijos conforme a sus convicciones religiosas, filosóficas y pedagógicas, pero, no obstante, el Tribunal Constitucional considera que:

$\left.{ }^{32} \mathrm{FJ} 5 .^{\circ}, b\right)$. 
«Esta última precisión debe entenderse referida a aquellas opciones pedagógicas que resulten de convicciones de tipo religioso o filosófico, puesto que el art. 14 de la Carta de los Derechos Fundamentales de la Unión Europea "se inspira tanto en las tradiciones constitucionales comunes a los Estados miembros como en el art. 2 del Protocolo Adicional al CEDH", sin que la referencia a las convicciones pedagógicas se encuentre entre las ampliaciones de este último precepto reconocidas en las explicaciones elaboradas bajo la autoridad del Praesidium de la Convención que redactó la Carta y actualizadas bajo la responsabilidad del Praesidium de la Convención Europea, y que, conforme establece la propia Carta en el Preámbulo y en su art. 52.7, han de servir a una interpretación genética de los derechos por ella reconocidos» ${ }^{33}$.

En este punto resulta criticable el Tribunal Constitucional porque las motivaciones pedagógicas aducidas por los demandantes en amparo responden a profundas convicciones ideológicas y filosóficas que, por lo demás, de ordinario subyacen en el fenómeno de la educación en casa, atinentes, en último término, a conceptualizar la escuela como un instrumento que entrega el monopolio de la educación al Estado cuando, a su juicio, corresponde a los padres el protagonismo en la educación de los hijos ${ }^{34}$.

\section{EL HOMESCHOOLING Y EL INTERÉS DEL MENOR}

Admitido que detrás del homeschooling existen importantes motivos de conciencia que podrían justificar su invocación como objeción, el siguiente paso lógico, tal y como hace el Tribunal Constitucional, es explicitar si constituye un modelo educativo idóneo para satisfacer el interés del menor a la educación. El interés del menor aparece como principio constitucional vertebrador de la protección de los menores de edad (art. 39 CE) y eje sobre el que gira cualquier actuación pública o privada seguida en relación con los mismos, y también, claro está, de la actividad educativa. Así, en el ámbito del Derecho internacional la Declaración de los Derechos del

33 FJ 6. ${ }^{\circ}$

${ }^{34}$ En el sentido también de admitir la educación en casa por motivos pedagógicos M. ${ }^{a}$ R. GarCía VilardelL, «El derecho educativo paterno a la formación religiosa y moral de los hijos: precisiones en torno a su alcance. Su aplicación al caso concreto del homeschooling», en J. R. Polo SABAu (coord.), Anuario de Derecho a la Educación, Madrid, Dykinson, 2012, pp. 148-149. En contra de la admisión por motivos pedagógicos C. GARCIMARTín MonTERO, «Educación en el Estado laico: ¿de quién es el derecho?», op. cit., pp. 86-87. 
Niño, aprobada por la Asamblea General de Naciones Unidas de 20 de noviembre de 1959, en el principio 7 dispone que: «El interés superior del niño debe ser el principio rector de quienes tienen la responsabilidad de la educación y orientación; dicha responsabilidad incumbe, en primer término, a sus padres». Por eso la imposición de un modelo educativo por los padres a los hijos debe respetar el principio de interés del menor que informa y, a la vez, limita el derecho de los padres a educar a sus hijos con arreglo a sus propias convicciones.

Consecuentemente con la finalidad de la educación en un Estado democrático, el art. 27.2 CE dispone como objeto de la misma «el pleno desarrollo de la personalidad humana en el respeto a los principios democráticos de convivencia y a los derechos y libertades fundamentales», precepto que ha sido calificado por la doctrina de auténtico ideario constitucional ${ }^{35}$. El precepto vincula, indefectiblemente, derecho a la educación con dignidad personal y con el libre desarrollo de la personalidad, lo cual, por un lado, es congruente con la posición privilegiada que tiene en el sistema el principio personalista en cuanto fundamento lógico y ontológico de todos los derechos y libertades fundamentales, y por otro, con la propia dimensión teleológica del derecho a la educación: educación en libertad y para la libertad. En congruencia con este planteamiento la legislación sobre educación considera el libre desarrollo de la personalidad y el respeto a los valores constitucionales como una de las finalidades esenciales del proceso educativo.

$\mathrm{El}$ art. 27.2 CE, además de explicitar el objeto de la educación y los valores transversales informadores del sistema educativo, público o privado, configura la educación como transmisión no sólo de conocimientos, sino también de valores ${ }^{36}$. El ideario constitucional vendría a tener un carácter limitador de la libertad de enseñanza y del derecho de los padres a educar a sus hijos con arreglo a sus propias convicciones ${ }^{37}$.

Ahora bien, la clave es el principio de interés del menor, que para su determinación en cada caso concreto debe atenderse a dos parámetros fundamentales: la efectividad del derecho a la educación y el respeto al ideario constitucional ${ }^{38}$. La jurisprudencia constitucional sobre el homes-

35 Por todos, M. SAlguero, Libertad de cátedra y derechos de los centros educativos, Barcelona, Ariel, 1997, p. 104.

${ }^{36}$ STC 5/1981, FJ 7.

37 B. AlÁEz Corral, «El ideario educativo constitucional como límite a las libertades educativas», Revista Europea de Derechos Fundamentales, núm. 17 (2011), pp. 123-128.

${ }_{38}^{38}$ M. A. Asensio Sánchez, La patria potestad y la libertad de conciencia..., op. cit., p. 76. 
chooling, si bien no alude explícitamente al interés del menor, sí lo hace implícitamente con términos más o menos claros como «educación integral». Así, la STC 260/1994 dispone que «el derecho a la libertad religiosa de los padres y, por tanto, cualquiera de sus manifestaciones, entre las que se incluye la libertad de enseñanza, tiene como límite el derecho de los menores a recibir una educación integral» ${ }^{39}$.

La STC 133/2010 alude, en cambio, al objeto de la educación establecido en el art. 27.2 CE y justifica precisamente la escolarización obligatoria a su efectividad:

«Y por lo que aquí más interesa, encuentra su justificación en la finalidad que ha sido constitucionalmente atribuida a la educación y al sistema diseñado para el desarrollo de la acción en la que ésta consiste, que "tendrá por objeto el pleno desarrollo de la personalidad humana en el respeto a los principios democráticos de convivencia y a los derechos y libertades fundamentales" (art. 27.2 CE). La educación a la que todos tienen derecho, y cuya garantía corresponde a los poderes públicos como tarea propia, no se contrae, por tanto, a un proceso de mera transmisión de conocimientos [cfr. art. 2.1.b) LOE], sino que aspira a posibilitar el libre desarrollo de la personalidad y de las capacidades de los alumnos [cfr. art. 2.1.a) LOE] y comprende la formación de ciudadanos responsables llamados a participar en los procesos que se desarrollan en el marco de una sociedad plural [cfr. art. 2.1.d) y k) LOE] en condiciones de igualdad y tolerancia, y con pleno respeto a los derechos y libertades fundamentales del resto de sus miembros [cfr. art. 2.1.b) y c) LOE]».

Este objetivo, complejo y plural, es el que, conforme al art. 27.2 CE, ha de perseguir el legislador y el resto de los poderes públicos a la hora de configurar el sistema de enseñanza dirigido a garantizar el derecho de todos a la educación, y el mandato de su consecución es el principio constitucional al que sirve la imposición normativa del deber de escolarización en el marco de la enseñanza básica obligatoria (arts. 9.2 LOCE y 4.2 LOE). Un principio, por lo demás, que no sólo opera como directriz que la Constitución impone a los poderes públicos, y muy singularmente al legislador (art. 27.2, 4, 5 y 8 CE), sino que integra el contenido de la dimensión prestacional del derecho de los niños a la educación (art. 27.1 CE). Incluso en el caso de que la decisión de los padres de no escolarizar a sus hijos pretendiera ampararse en el ejercicio del derecho reconocido en el art. 27.3

${ }^{39} \mathrm{FJ} 1 .^{\circ}$ 
CE, la imposición normativa del deber de escolarización y la garantía jurisdiccional de su efectividad encontrarían justificación constitucional en el mandato dirigido a los poderes públicos por el art. 27.2 CE y en el derecho a la educación que el art. 27.1 CE reconoce a todos, incluidos los hijos de los ahora recurrentes en amparo [STC 260/1994, de 3 de octubre (RTC 1994, 260), FJ 2. ${ }^{\circ}$ in fine].

Sin embargo, el problema no es determinar si la escolarización obligatoria constituye un medio adecuado para satisfacer los fines constitucionales del sistema educativo (art. 27.2 CE), cosa que por lo demás los recurrentes no niegan ${ }^{40}$, sino si el modelo educativo del bomeschooling es compatible con dichos fines. Las partes recurrentes alegan que en los países en que se admite el homeschooling existen controles administrativos de carácter periódico sobre la evaluación formativa del niño y de los contenidos que se transmiten ${ }^{41}$. No obstante, el Tribunal Constitucional considera que, si bien la transmisión de conocimientos en este modelo educativo es susceptible de control y verificación por la Administración, no ocurre lo mismo con los fines educativos de garantizar el libre desarrollo de la personalidad en el marco de una sociedad democrática.

Sin embargo, según hemos indicado, ésta no es la única finalidad que deben perseguir los poderes públicos a la hora de configurar el sistema educativo, en general, y la enseñanza básica, en particular, que han de servir también a la garantía del libre desarrollo de la personalidad individual en el marco de una sociedad democrática y a la formación de ciudadanos respetuosos con los principios democráticos de convivencia y con los derechos y libertades fundamentales; una finalidad ésta que se ve satisfecha más eficazmente mediante un modelo de enseñanza básica en el que el contacto con la sociedad plural y con los diversos y heterogéneos elementos que la integran, lejos de tener lugar de manera puramente ocasional y fragmentaria, forma parte de la experiencia cotidiana que facilita la escolarización. En definitiva, la medida propuesta como alternativa en la demanda de amparo quizás resulte menos restrictiva desde la perspectiva del derecho de los padres reconocido en el art. 27.3 CE, pero en modo algu-

${ }^{40}$ En primer lugar, los recurrentes no niegan que la configuración de la enseñanza básica como un periodo de escolarización obligatoria en centros docentes homologados represente una medida adecuada o congruente respecto de la satisfacción de la finalidad que le es propia: «[1]a garantía del derecho individual a la educación básica obligatoria y el interés colectivo de que toda persona se forme en el conocimiento y respeto de los principios democráticos y de los derechos fundamentales legitiman determinadas formas de restricción de la libertad de enseñanza. Por tanto, parece que la medida es adecuada» (FJ 8. ${ }^{\circ}$.

${ }^{41}$ FJ 8. ${ }^{\circ}$ 
no resulta igualmente eficaz en punto a la satisfacción del mandato que la Constitución dirige a los poderes públicos en el art. 27.2 CE y que constituye, al tiempo, el contenido del derecho a la educación reconocido en el art. 27.1 CE. Por lo demás, el Tribunal Europeo de Derechos Humanos ha reconocido que la apreciación de que estos objetivos no pueden «ser satisfechos en la misma medida por la educación en el propio domicilio, incluso en el caso de que ésta permitiera a los niños la adquisición del mismo nivel de conocimientos que proporciona la educación primaria escolar [...] no es errónea y que cae dentro del margen de apreciación que corresponde a los Estados signatarios en relación con el establecimiento y la interpretación de las normas concernientes a sus correspondientes sistemas educativos» (caso Konrad v. Alemania, decisión de admisibilidad de 11 de septiembre de 2006, núm. 35504/2003) ${ }^{42}$.

El Tribunal Constitucional plantea una de las cuestiones más criticadas del modelo del homeschooling: la falta de socialización de los alumnos y la posibilidad de ser objeto de especial adoctrinamiento mediante una educación «guetizada» y atentatoria contra los principios del sistema democrático y el libre desarrollo de la personalidad (art. 27.2 CE). Para evitar este peligro y garantizar el interés del menor, el Alto Tribunal opta por limitar los derechos educativos paternos rechazando el modelo de la educación en casa que, por otro lado, reconoce menos restrictivo de los derechos paternos que el de escolarización obligatoria.

En buena medida éste es también el sentido del voto particular de Gimeno Sendra en la STC 260/1994, de 3 de octubre:

«Porque consta en las actuaciones que los niños no estaban escolarizados (a salvo, claro está, que por tal se entienda la formación dentro de la propia secta) [...]. El presente recurso de amparo plantea el, ante este Tribunal, novedoso problema de determinar si el derecho a la educación consiste en la "total libertad de los padres para orientar (a los hijos) hacia las convicciones morales, religiosas o filosóficas que crean más adecuadas a su formación intelectual y somática" (FJ 8. in fine de la resolución recurrida) - en cuyo caso dicho derecho se confundiría con la "libertad ideológica y religiosa" del art. 16, reconduciéndose al derecho contemplado en el art. 27.3-, o si dicho derecho consiste esencialmente en el derecho del niño a ser escolarizado con la consiguiente obligación de los poderes públicos de procurar dicha escolarización, incluso obligatoriamente, si ello fuera del todo punto necesario».

${ }^{42} \mathrm{FJ}^{\circ} .^{\circ}$

Foro, Nueva época, vol. 15, núm. 2 (2012): 185-212 
A mi parecer, el art. 27.1 contempla el segundo de los citados derechos, cuyo único titular originario son los niños, aun cuando, en circunstancias normales, los padres hayan de ejercitarlo a través de la representación.

Por último, las partes recurrentes alegan la existencia eventual de un conflicto de derechos y que, conforme a la doctrina constitucional, debe resolverse atendiendo al principio de proporcionalidad. Así entienden que el deber de escolarización debe satisfacer el principio de proporcionalidad, y en este caso no ocurre porque las ventajas obtenidas con la limitación del derecho de los padres no son superiores a las desventajas de los padres titulares de la libertad de enseñanza. Sin embargo, el Tribunal Constitucional rechaza los argumentos de los recurrentes por tres razones:

1. ${ }^{\circ} \quad$ Los padres se fijan exclusivamente en los aspectos del derecho a la educación como transmisión de conocimientos «obviando cualquier consideración acerca del mejor cumplimiento que razonablemente cabe esperar por parte del sistema de escolarización obligatoria de los complejos fines que el art. 27.2 CE atribuye a la educación a la que, por otra parte, los niños tienen derecho de acuerdo con el art. 27.1 CE» ${ }^{43}$.

2. ${ }^{\circ} \quad$ La escolarización obligatoria limita los derechos educativos paternos, pero no les impide a los padres ejercer su función educadora fuera del sistema escolar ${ }^{44}$.

3. Pero la razón más importantes es que los padres pueden crear un centro docente ${ }^{45}$.

43 FJ 9.

${ }^{44}$ «En segundo término, el alcance de la restricción operada por la decisión de configurar la enseñanza básica como un periodo de escolarización obligatoria en el contenido protegido por el derecho de los padres reconocido en el art. 27.1 y 3 CE ha de ser en todo caso relativizado en la medida en que, según se ha advertido ya, no impide a éstos influir en la educación de sus hijos, y ello tanto fuera como dentro de la escuela: dentro de ella porque los poderes públicos siguen siendo destinatarios del deber de tener en cuenta las convicciones religiosas particulares, y también fuera de ella porque los padres continúan siendo libres para educar a sus hijos después del horario escolar y durante los fines de semana, de modo que el derecho de los padres a educar a sus hijos de conformidad con sus convicciones morales y religiosas no resulta completamente desconocido. Según ha reconocido el Tribunal Europeo de Derechos Humanos, la "escolarización obligatoria en el ámbito de la educación primaria no priva a los padres demandantes de su derecho a ejercer sobre sus hijos las funciones de educadores propias de su condición parental, ni a guiar a sus hijos hacia un camino que resulte conforme con sus propias convicciones religiosas o filosóficas" (véase, mutatis mutandis, Kjeldsen, Busk Madsen y Pedersen v. Dinamarca, TEDH, 5, 1976, pp. 27-28, apartado 54; Efstratiou v. Grecia, Sentencia de 18 de diciembre de 1996, TEDH, 71, 1996; Repertorio de Sentencias y Decisiones, 1996-VI, p. 2359, apartado 32; Konrad v. Alemania, Decisión de admisibilidad de 11 de septiembre de 2006, núm. 35504/2003)» (FJ 9. ${ }^{\circ}$.).

${ }^{45}$ «Pero, sobre todo - y ésta es la tercera de las razones señaladas-, debemos excluir 
Ahora bien, los argumentos empleados por el Tribunal Constitucional son objeto de fundada crítica:

1. ${ }^{\circ}$ Así, en relación a la afirmación de que los padres sólo se fijan en el aspecto de la enseñanza como transmisión de conocimientos, parece el Tribunal dar por sentado que los fines del art. 27.2 CE estaban excluidos de la educación en casa introduciendo un ámbito de sospecha sobre la actitud de los padres que los hechos no acreditan. En el fondo late la idea de que sólo la educación dentro del sistema escolar permite una educación abierta que desarrolle la personalidad del menor dentro de los valores constitucionales.

2. ${ }^{\circ}$ La escolarización en la argumentación del Tribunal limita los derechos educativos de los padres, pero no impide que eduquen a sus hijos fuera del horario extraescolar. Se trata de una argumentación incorrecta y peligrosa, si se me permite la expresión, porque los derechos educativos paternos tienen su efectividad no sólo, ni principalmente, en el hogar, sino también en la escuela, porque la educación de un menor exige unidad y coherencia entre la educación recibida en casa y en la escuela.

3. ${ }^{\circ} \quad$ Por último, el argumento que el Tribunal considera más importante es la posibilidad que el art. 27.6 CE atribuye a los padres para crear un centro docente en el que se importa su modelo educativo ideal. Además, no puede pretenderse que fundar un colegio sea algo sencillo y a lo que estén dispuestos o puedan la mayoría de los padres ${ }^{46}$.

En realidad, el Tribunal Constitucional rechaza el sistema del homeschooling y entiende, de un lado, que los derechos educativos paternos

que la restricción de este último derecho resulte manifiestamente excesiva en tanto que los padres pueden ejercer su libertad de enseñanza a través del derecho a la libre elección de centros docentes (art. 27.6 CE). Efectivamente, era ésta, y no la que representa el incumplimiento del deber legal de escolarizar a sus hijos, la opción constitucional abierta a los recurrentes como vía de plasmación de su distinta orientación educativa, y ello por más que en su articulación debiera garantizarse en todo caso, como no podría ser de otra manera en virtud del art. 27, apartados 2, 5 y 8, CE, el respeto, "[d] entro del marco de los principios constitucionales, [de] los derechos fundamentales, del servicio a la verdad, a las exigencias de la ciencia y a las restantes finalidades necesarias de la educación mencionadas, entre otros lugares, en el art. 27.2 de la Constitución y en el art. 13.1 del Pacto Internacional sobre Derechos Económicos, Sociales y Culturales (RCL 1977, 894) y, en cuanto se trate de centros que, como aquellos a los que se refiere la Ley que analizamos, hayan de dispensar enseñanzas regladas, ajustándose a los mínimos que los poderes públicos establezcan respecto de los contenidos de las distintas materias, número de horas lectivas, etc." [STC 5/1981, de 13 de febrero (RTC 1981, 5), FJ 8. $\left.{ }^{\circ}\right) \gg\left(\right.$ FJ 9..$\left.^{\circ}\right)$.

${ }^{46}$ C. Garcimartín Montero, «Educación en el Estado laico: ¿de quién es el derecho?», op. cit., pp. 87-88. 
están limitados por el derecho del menor a una educación integral y, de otro, la existencia de un derecho educativo del Estado concurrente con el de los padres ${ }^{47}$. Es más, el Tribunal Constitucional se decanta por la prevalencia del Estado en la educación y limita, de forma injustificada, el protagonismo de los padres y de la sociedad en la educación.

47 J. M. MARTí, «El homeschooling en el Derecho español», Revista General de Derecho Canónico y Eclesiástico del Estado, p. 33. 